\title{
Statistical Parameter Mapping
}

National Cancer Institute

\section{Source}

National Cancer Institute. Statistical Parameter Mapping. NCI Thesaurus. Code C94988.

Converting throughout a region the pixels' (voxels') activity concentrations to a

difference from a reference and then normalized by a standard deviation. 